\title{
Trafik Sinyalizasyon Sisteminde Akıllı Kavşak Kontrolü
}

\author{
Nihat Pamuk ${ }^{1 *}$ \\ 1* Zonguldak Bülent Ecevit Üniversitesi, Mühendislik Fakültesi, Elektrik Elektronik Mühendisliği Bölümü, Zonguldak, Türkiye, (ORCID: 0000-0001-8980-6913), \\ nihatpamuk@gmail.com
}

(1st International Conference on Applied Engineering and Natural Sciences ICAENS 2021, November 1-3, 2021)

(DOI: 10.31590 /ejosat.998887)

ATIF/REFERENCE: Pamuk, N. (2021). Trafik Sinyalizasyon Sisteminde Ak1llı Kavşak Kontrolü. Avrupa Bilim ve Teknoloji Dergisi, (28), 312-319.

\begin{abstract}
$\ddot{O} \mathbf{z}$
Son yıllarda artan nüfus artışıyla birlikte, bazı bölgelerde trafik yoğunluğu artışı da oluşmaktadır. Büyük şehirlerde nüfusa bağlı olarak yapımına başlanılan yeni yollarla birlikte kavşaklardaki trafik yoğunluğu da artış göstermekte, bu durum büyük şehirlerde çözülmesi gereken trafik problemleri haline dönüşmektedir. Günümüzde oluşan trafik yoğunluğu sebebiyle, araçların bir noktadan başka bir noktaya giderken karşılaşabilecekleri gecikme sorunlarının tespiti için farklı veriler kullanılmaktadır. Gecikme, kavşaklarda bulunan trafik lambaları için en uygun sürenin belirlenmesi ve bu noktalardaki vasıtaların yoğunluklarının tespitinde kullanılan en önemli faktörlerden birisidir. Bu durum trafiğin yoğun olarak oluştuğu bölgelerde çözüm üretme aşamasında yetersiz kalmaktadır. Bundan dolayı trafik yoğunluğu, kırmızı 1şıkta bekleme süreleri ve beklemekte olan vasıta sayısı ile trafik sinyalizasyon sistemlerinin tasarımında kritik öneme sahip değişkenler olarak belirlenmektedir. Bu çalışmada bir kavşaktaki trafik ışıklarının zamanlama sürelerinin ve araç yoğunluğu problemlerinin çözümü ele alınmıştır. Yapılan uygulama ile trafik yoğunluğu, kırmızı 1şıkta bekleme süreleri, kırmızı 1şıkta bekleyen vasıta sayısı verileri değişken olarak bir model üzerinde kullanılarak örnek bir sinyalizasyon yöntemi sunulmuştur.
\end{abstract}

Anahtar Kelimeler: Trafik 1şıkları, Akıllı kavşak, Sistem modelleme, Sinyalizasyon, Arduino, Sensör.

\section{Smart Intersection Control in Traffic Signaling System}

\begin{abstract}
Along with the increasing population growth in recent years, there has been an increase in traffic density in some regions. The traffic density at the intersections increases with the new roads that are started to be built in big cities depending on the population, and this turns into traffic problems that need to be solved in big cities. Due to the current traffic density, different data are used to determine the delay problems that vehicles may encounter while traveling from one point to another point. Delay is one of the most important factors used in determining the most appropriate time for traffic lights at intersections and determining the densities of vehicles at these points. This situation is insufficient in producing solutions in regions with heavy traffic. Therefore, traffic density, waiting times at red lights and the number of vehicles waiting are determined as critical variables in the design of traffic signaling systems. In this study, the timing of traffic lights at an intersection and the solution of vehicle density problems are discussed. With the application, an exemplary signaling method is presented by using the data of traffic density, waiting times at red light, number of vehicles waiting at red light as variables on a model.
\end{abstract}

Keywords: Traffic lights, Smart intersection, System modeling, Signaling, Arduino, Sensor.

\footnotetext{
*Sorumlu Yazar: nihatpamuk@gmail.com
} 


\section{Giriş}

Dünya genelinde artan teknoloji ile birlikte fosil yakıt kullanan araçların üretimi kolaylaşmış dolayısıyla motorlu araç kullanımı oranı günümüzde yüksek oranlara ulaşmıştır. Bununla birlikte karayollarında trafik hacmi artmıştır. $\mathrm{Bu}$ artış trafikte istenmeyen kazalara sebep olmaktadır. Trafik kazalarının önüne geçmek maksadıyla trafikte çeşitli türlerde sinyalizasyon sistemleri kullanılmaya başlanmıştır. Ancak günümüzde uygulamaya giren trafik sinyalizasyon sistemleri, artan trafik yoğunluğunu düzene sokabilecek nitelikte tasarlanmadığından trafikte çok fazla duraklamalara neden olmaktadır. Bu durum motorlu araç sürücülerine hem vakit kaybettirmekte hem de daha çok yakıt sarfiyatına sebep olmaktadır. Fazladan yapılan yakıt sarfiyatı hem ülkemizin maddiyatına hem de canlılara ve çevremize zarar vermektedir.

Literatürde kavşaklardaki akıllı sinyalizasyon benzetim uygulamaları üzerine birçok çalışma yapılmıştır. Yapılan çalışmalarda genellikle bulanık mantık denetimleri ve yapay sinir ağları kullanılarak karar destek yapıları incelenmiştir. 1977 yılında Mandani ve Pappis tarafindan önerilen sinyal devresi sayesinde trafik kuyruk uzunluğunun boyutlandırılması, yaklaşım kolu trafik karmaşasının giderilmesi ve bekleme süresinin değişken olarak alınarak incelenmesi için bir uygulayıcı model geliştirilmiştir (Pappis \& Mamdani, 1977). 1995 yılında Tzes tarafından trafikteki araç yoğunluğunun önlenebilmesi için akıllı trafik sinyal kontrolör tasarımı gerçekleştirilmiştir (Tzes, Nikolakopoulos, \& Koutroulis, 2005). Kim, McShane ve Tzes tarafından bulanık mantık çalışma şartlarına uyumlu bir benzetim modeli yapılmıştır. Modelin sabit zamanlı sinyalizasyon sistemi ile karşılaştırılması incelenmiştir (Tzes, McShane, \& Kim, 1995).

Jongwan Kim tarafından yapılan uygulama algoritması ile birbirinden ayrık ve dört yönlü denetlenebilen kavşaklar için bir benzetim modeli geliştirilmiştir (Kim \& Jongwan, 1997). Bu benzetim modeli ile ayrık ve aynı zamanlı denetlenebilir yapının sinyalizasyon ile göstermiş olduğu farklı yönleri belirlenmiştir (Öztürk \& Çalış, 2017). J.P. Niittymaki tarafından ayrı ayrı ve iki yönlü denetlenebilen kavşaklar için geliştirilmiş denetleme algoritmasının benzetimi yapılarak trafik uyarlamalı denetim esnasındaki gecikme ve duruş oranı gibi performans kıstasları karşılaştırılmıştır (Niittymaki \& Jarkko, 1997). Jumar ve Hoyer tarafından ise değişiklikleri açıkça belirtecek şekilde faz düzenini gösteren bir benzetim model yapısı gerçekleştirilmiştir (Hoyer \& Jumar, 1994). Söz konusu modelde, trafik yoğunluğu ile kırmızı işarete sahip trafik lambasının ürettiği sinyal değerlerinin doğru orantılı faz zamanı değerleri belirlenmiş ve uygulama çalışmaları yapılmıştır (Kelsey, Bisset, \& Jamshidi, 1993).

Günümüzde kullanılan akıllı sistemler yardımı ile insanların trafikte fazladan zaman harcamalarını azaltacak şekilde yeniden düzenlemeler yapılmaktadır. $\mathrm{Bu}$ amaçla kavşaklardaki sinyalizasyon sistemleri trafik yoğunluğunu algılayacak şekilde geliştirilmektedir. Araç yoğunluğu bulunan tarafa geçiş üstünlüğü verilecek şekilde uygun program yapısının belirlenmesi gerekmektedir. Akıllı trafik sinyalizasyon benzetim çalışması ile trafik akışı algılanmakta, trafik hacminin fazla olduğu yöne geçiş önceliği verilerek trafik akışı hızlandırılmaktadır. Böylece dört kavşaklı bir yol güzergâhında herhangi bir yönde araç bulunmuyor ve sadece ilgili yönde araç bulunması durumunda hiçbir bekleme durumu gerçekleşmeden sinyalizasyon sistemi çalışarak ilgili araç için yeşil ışığın yanmasını sağlamaktadır.

\section{Trafik Sinyalizasyonu}

Trafik Sinyalizasyonu, 19. yüzyılın sonlarında ulaşım alanında bulunan işletme kollarından birini oluşturmaktadır. 1960 yılından sonra dünya genelinde çoğunlukla kentsel bölgelerdeki trafik sinyal lambalarının kullanıldığı görülmektedir (Chai, Shen, \& Ye, 2006). Ülkemizde ise trafik sinyalizasyonu alanında ilk çalışmalar yirminci yüzyılda başlamış olup, İstanbul, Ankara ve İzmir gibi büyük şehirlerdeki önemli kavşaklar dışında fazla kullanılmamıştır. Trafik sinyalizasyon sistemleri, trafik hacminin belirli seviyeden fazla olması durumlarında kullanılmaktadır. Tablo 1'de minimum araç trafiği için belirlenmiş olan yoğunluk seviyeleri gösterilmiştir. Teknolojinin ilerlemesiyle trafik sinyalizasyon sistemi, sensörler, kameralar, tabletler ve bilgisayar aracılığıyla yoğunluk denetimi yapılmaktadır (Tunç, 2003).

Tablo 1. Minimum vasita trafiği için belirlenmiş olan yoğunluk seviyeleri (Tunç, 2003)

\begin{tabular}{c|c|c|c}
\hline \multicolumn{2}{c|}{$\begin{array}{c}\text { Her bir yaklaşım } \\
\text { için şerit sayısı }\end{array}$} & \multirow{2}{*}{$\begin{array}{c}\text { Ana yoldaki } \\
\text { vasıta / saat } \\
\text { trafiği }\end{array}$} & $\begin{array}{c}\text { Yan yoldaki } \\
\text { vasita / saat } \\
\text { trafiği }\end{array}$ \\
\cline { 1 - 2 } Ana yol & Yan yol & 520 & 155 \\
\hline 1 & 1 & 610 & 160 \\
\hline$\geq 2$ & 1 & 650 & 210 \\
\hline$\geq 2$ & $\geq 2$ & 550 & 215 \\
\hline 1 & $\geq 2$ & \multicolumn{2}{c}{} \\
\hline
\end{tabular}

\section{Trafik Sinyali Yönetim Teknikleri}

Trafik sinyalizasyon sistemleri motorlu taşıtlar ve yayaların 1şıklı ikazlar ile uyarılması ve geçiş üstünlüklerinin tanzim edilmesini sağlayan sistemlerdir (Firdous, Din Iqbal, Ghafoor, Qureshi, \& Naseer, 2019). Taşıt ve yayaların buluştuğu yollarda sinyalizasyon sisteminin oluşturulası yönündeki şartlar mühendislik uygulamaları kullanılarak yapılmaktadır. Sistem kurulmadan önce uygulamaya girecek olan bölümün topoğrafyasına, trafik akışının yönlerine göre taşıt veya yaya yoğunluklarına uyumlu olacak şekilde kavşaklar belirlenmekte ve uygun yönetim planlaması yapılmaktadır.

Özellikle büyük şehirlerde trafik sinyalizasyon sistemine uygun kavşaklar belirlenmektedir. Şehirlerin sürekli olarak büyümesi ve vasıta kullanım oranının artması sonucunda sürekli olarak trafik yoğunluğu ile karşı karşıya gelinmektedir. Bu yoğunluk ile birlikte sinyal sürelerinin devamlı olarak aktif tutulması oldukça büyük iş yoğunluklarına neden olmaktadır (Azimirad, Pariz, \& Sistani, 2010). Sinyalize kontrol uygulamalarının başlıca parametreleri; sinyal zamanları ve faz değerleridir. Sinyalize yönetim tekniklerinde trafik kontrolü genellikle iki, üç veya dört yönlü olarak gerçekleştirilmektedir (Ramzanzad \& Rashidy Kanan, 2013).

\subsection{Sabit Zamanlı Sinyal Yönetimi}

Sabit zamanlı sinyal yönetimi, araç yoğunluğunun sıklıkla değişim göstermediği, düzenli ve hesaplanabilir kavşaklarda kullanılmaktadır (Dağüstü, 2010). Sabit zamanlı sinyal yönetiminde, trafik yoğunluğu sonucuna göre hesaplanan sinyal zamanları ve faz sıralamaları kavşağa kaydedilir. Kavşakta bulunan araç ve yayaların belirlenen süreler içerisinde hacimsel olarak değişkenlik göstermediği kabul edilir. Ülkemizde genellikle sabit süreli trafik sinyalizasyon sistemleri kullanılmaktadır. Sabit süreli sinyalizasyon sistemlerinde, kavşaklar için farklı konumlardan gelen taşıtlar ile yaya trafiğine göre önceden hazırlanmış süre programlamalarına eş zamanlı 
olarak geçiş üstünlüğü planlaması yapılarak belirlenmektedir. Sabit zamanlı sinyalizasyon sistemlerinin en önemli avantaj1, trafik yoğunluğunun düzenli ve öngörülebilir olduğu kavşaklarda veya ana yol ile yan yol birleşim yerlerinde ana yolun sürekli olarak kullanılabilmesini sağlamasıdır (Balta \& Özçelik, 2019).

\subsection{Trafik Uyarlamalı (TU) Sinyal Yönetimi}

Trafik uyarmalı sinyal yönetimi genel itibariyle, anayollardaki vasita yoğunluğunun çok daha fazla olduğu yerlerde kullanılmaktadır. Trafik uyarmalı sinyal yönetim sisteminin amacı, anayollardaki trafik lambalarının yeşil renkte kalma sürelerinin gereksiz yere kesilmesinin engellenmesi ve değişken trafik yoğunluklara göre dönüş yönlerindeki sinyalizasyon sistemlerinin anlık olarak çözüm üretmesini sağlamaktır (Güler, 2013). Bu yönetim şeklinin en önemli bileşeni kavşaktaki ikinci derecede önemli ana yollar dışındaki yan yollara ve dönüş kısımlarına koyulan sensörlerdir. $\mathrm{Bu}$ yollardan kavşaklara doğru gelen vasıtalar sensörler aracılığıyla tespit edilmekte ve süresi içinde önceden belirlenen veya programlanan zaman dilimi içerisinde yeşil renkteki lambanın yanmasını sağlamaktır. Eğer belirlenen yönden vasıtalar gelmeye devam ediyor ise, yeşil renkteki lambanın yandığı süre diliminde yine önceden belirlenen zaman aralığını arttırmaya devam etmekte ve vasıtaların geçmesine izin vermektedir. Bununla birlikte kesişen kavşaklardaki programlanan süreyi daha etkin olarak kullanabilmenin bir diğer yolu da kavşaklar ve trafik kontrol merkezi arasındaki iletişimin düzenli olarak sağlanmasıdır. $\mathrm{Bu}$ sayede tüm iletişim sistemleri tek bir kontrol merkezi ile (trafik kontrol merkezi) kontrol edileceğinden dolayı, önceden belirlenen süreleri değiştirmek mümkün olmaktadır. Bununla birlikte trafikteki yoğunluk kesişim süreleri ayarlanmaktadır. Sistemde bulunan sensörler veya mobese kameralarından elde edilen veriler kullanılarak sistem verimlilik düzeyi arttırılmaktadır.

\subsection{Dinamik Sinyal Yönetimi}

Dinamik sinyal yönetim sisteminde hem anayol hem de yan yollar için vasita yoğunluk değerleri sensörler aracilığıyla belirlenmektedir. Önceden ayarlanmış olan trafik sinyalizasyon planlamaları neticesinde sinyal zamanları anlık ihtiyaçlara göre değiştirilip düzenlenmektedir (Yılmaz, Altınkaya, \& Ekmekçi, 2019). Dinamik sinyalizasyon yönetiminin uygulandığ kavşaklarda vasıta yoğunluğu arttıkça önceden belirlenen en düşük ve en yüksek zaman dilimindeki yeşil renkte yanan lamba süreleri sürekli olarak değişkenlik göstererek sinyal denetimi yapilacaktır.

\subsection{Adaptif Sinyal Yönetimi}

Adaptif sinyal yönetimi, son yıllarda geliştirilmekte olan vasıta algılayıcı denetimlerinde iletişim ve mikro kontrol teknolojilerine bağlı olarak gelişmekte ve ileri trafik yönetim sistemi faktörlerinden biri olarak tanımlanmaktadır (Gonca \& Gülsün, 2019). Sinyal optimizasyonu konusundaki çalışmalar içerisinde "adaptif sinyal yönetimi" ileri bir teknik olarak tanımlanmaktadır. Son zamanlarda ülkemizde de bu konuda önemli atılımlar yapılmaktadır. Adaptif sinyal yönetim sisteminde tüm yönlerden gelen vasitalar algilanmakta ve vasita yoğunluğuna göre geçiş üstünlüğü ilgili yöne verilmektedir. Vasıtalar kavşağa yaklaştı̆̆ında, kavşaklardan çıkışta ve vasitaların oluşturduğu kuyruk uzunluğunun belirlenmesi amacıyla ilgili kavşağa belirlenen mesafelerde algılayıcılar ve sensörler yerleştirilmektedir.
Algılayıcılardan ve sensörlerden gelen sinyal raporlarına göre elde edilen veriler farklı algoritmalarla işlenmekte ve ilgili kavşağın ihtiyacı olan zamanlar eşgüdümlü olarak belirlenmektedir. Sistemin başlıca avantajları olarak; trafik akışındaki değişimlere anında cevap verebilmesi, trafik kuyruk mesafesinin algilanarak oluşabilecek gecikme sürelerinin en alt düzeye çekilmesine olanak tanıması ve vasıta hızına bağlı olarak gecikme sürelerinin program algoritmasında otomatik olarak ayarlanabilmesine imkân tanımasıdır (Aavani, Sawant, Sawant, \& Deshmukh, 2017).

\subsection{Yeşil Dalga Koordinasyonu ve Sinyal Yönetimi}

Yeşil dalga koordinasyonunda birbirini takip eden ve optimal sinyalizasyon yönetimi yapılmış olan kavşaklarda, bir kavşaktan yeşil ışıkta harekete başlayan vasıtaların yapılacak olan koordinasyon sayesinde diğer sinyalizasyon yönetimi yapılmış olan kavşaklarda da kırmızı 1şı̆̆ dalga şeklinde geçmelerini sağlanmaktadır (Ozkaya \& Seyfi, 2016).

\section{Sistem Materyalleri}

\subsection{2x16 - Led Ekran ve I2C Modülü}

Lcd ekran modülünde, arduino kartı üzerinden atanan trafik kavşaklardaki vasıtaların hızları anlık olarak izlenebilmektedir. Kavşaklarındaki ışık renklerine göre yavaş veya hızlı trafik akış yoğunlukları oluşturulmaktadır. Kavşaklarda yeşil renk yönündeki trafik akışı hızlanmakta, kırmızı renk yönündeki trafik akışları ise yavaşlamaktadır. Oluşan bu hız değişimleri Lcd ekran üzerinden görüntülenmektedir. Şekil 1'de 2x16 - Lcd ekran ve I2C modülü gösterilmiştir.
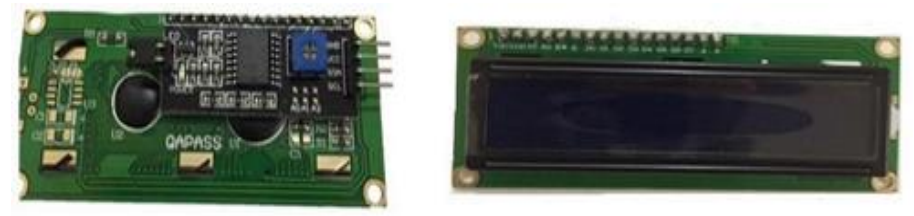

Şekil 1: 2x16 - Lcd ekran ve I2C modülü

\subsection{Arduino Mega Modülü}

Arduino Mega Modülü, Atmega 2560 temelli programlanabilir mikro denetleyici özelliğine sahip kart modülüdür. Arduino Mega Modülünde 54 adet sayısal giriş ve çıkış uçları bulunmakta olup, bunların 15 tanesi PWM çıkış ucu olarak kullanılmaktadır. Modül üzerinde 16 adet analog giriş ucu, 4 adet donanımsal seri port girişi (UART), $16 \mathrm{Mhz}$ çalışma frekansında kristal yapıya sahip USB güç soketi, ICSP konektörü ve reset tuşu bulunmaktadır (Tataru \& Druga, 2019). Şekil 2'de Arduino Mega Modülü gösterilmiştir.

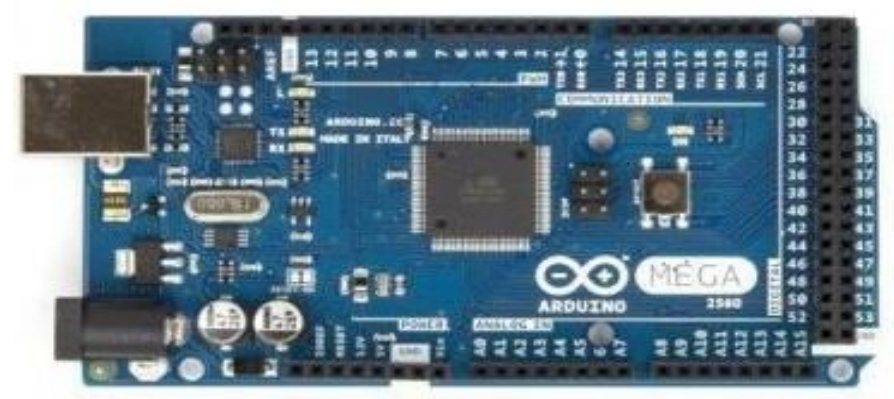

Şekil 2: Arduino mega modülü 


\subsection{Algilayıcılar}

Arduino Mega Modülü için gerekli olan algılayıcılar mikro denetleyici gibi zaman ve verilerin işlenmesi aşamasında önemli bir yer tutmaktadır. Algılayıcılar, termal veya mekanik değerleri ölçerek elde edilen değerleri elektrik sinyallerine dönüştürürler. Mekatronik sistemler elektriksel çıkış işareti veren algılayıcılarla birlikte kullanılırlar. Çıkış işaretinin özellikleri algılayıcıların ölçüm kriterlerine bağlı olarak değişir. Dönüştürücü ve invertör devreleri, 0-20 mA, 4-20 mA veya $0-10 \mathrm{~V}$ gibi elektrik büyüklükleri giriş sinyaline çevirirler. Sistemde yüksek frekans bozucuları bulunması durumunda ise, giriş sinyalinin etkileşim düzeyini düşürmek amaciyla alçak geçiren filtreler kullanılır. Algılayıcı işareti bir mikroişlemci vasıtasıyla kullanılıyor ise, mutlaka "Örnekle - Tut" devresi ile birlikte analog-sayısal dönüştürücü kullanılması gerekmektedir.

\subsection{Ultrasonik Mesafe Sensörü (HC-SR04)}

HC-SR04 ultrasonik mesafe sensörü, ses dalgaları yardımıyla trafikte oluşacak olan kuyruk uzunluğunun ölçümü için kullanılacak olan devre elemanıdır. Ses dalgalarını algılayabilmek için, ultrasonik mesafe sensörünün üstünde bir adet alıcı ve verici ucu bulunmaktadır. Şekil 3'te Ultrasonik mesafe sensörü gösterilmiştir.

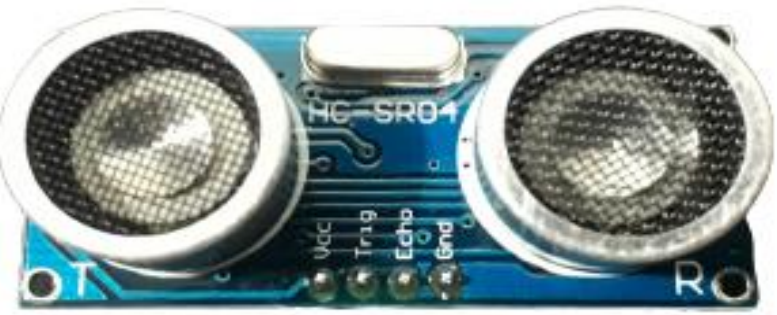

Şekil 3: Ultrasonik mesafe sensörü

Ses dalgaları verici ucundan yayılmaktadır. Verici ucundan yayılan ses dalgaları herhangi bir yüzeye çarparak geri dönmekte ve alıcı uç tarafindan geri dönen ses dalgası algılanmaktadır. $\mathrm{Bu}$ olayın gerçekleşmesi için gerekli olan zaman ile trafikte oluşacak olan kuyruk uzunluğunun ölçümü yapılmaktadır. HC-SR04 ultrasonik mesafe sensörü $2 \mathrm{~cm}$ ile $4 \mathrm{~m}$ arasında ölçüm yapabilmektedir (Samadi, Rad, Kazemi, \& Jafarian, 2019). HCSR04 ultrasonik mesafe sensörü ile yapılan ölçümler $3 \mathrm{~mm}$ hassasiyetinde gerçekleştirilmektedir. Ultrasonik mesafe sensörünün üzerinde 4 adet giriş pini bulunmaktadır. Bu pinler sirasiyla 5 voltluk Vec pini, Trigger pini, Echo Pini ve Ground pinleridir. Vcc pinine 5 voltluk gerilim sinyali uygulanarak verici üzerinden bir ses dalgası yayılımı sağlanır. Yayılan ses dalgası bir yüzeye çarparak geri dönmekte ve geri dönen ses dalgası alıcı üzerindeki Echo pini üzerine gerilim sinyali uygulamaktadır. Ses dalgasının yayılması ve geri yansıması arasındaki geçen süre kullanılarak sensör üzerinden mesafe bilgisi hesaplanır. Bu çalışmada, kavşağa gelen dört farklı yol için birbirinden farklı olacak şekilde belirli uzaklıklardaki sensörlerden alınan veriler karşılaştırılarak vasıta sayıları yardımı ile yoğunluk hesabı yapılmaktadır. Elde edilen yoğunluk hesabına göre geçiş üstünlüğü ilgili şeride aktarılmaktadır.

\section{Uygulama Çalışması}

Bu çalışmada akıllı kavşak yönetim sistemi üç ana bölümden oluşmaktadır. İlk bölüm sinyalizasyon sistemi, ikinci bölüm algılayıcı devre sistemi, üçüncü bölüm ise kontrolcü yapıya sahip olan devre sistemidir. Algılayıcı devreler kavşaklardaki vasıta yoğunluk durumunu ilgili sensörlerden aldığ 1 veriler ile birlikte kontrolcü devresini iletirler. Kontrolcü devreler gelen verileri değerlendirir. Kontrolcü devre içerisinde gömülü olan yazılım sayesinde mesafe bilgileri, ilgili kavşaklara gelen yollardaki vasıta sayısı bilgileri ve sinyalizasyon bilgileri karşılaştırılarak en uygun çözüm elde edilir. Şekil 4'te sistemin sembolik akış diyagramı gösterilmiştir. Şekil 5 'te tasarlanan sinyalizasyon sisteminin proteus programındaki devre şeması gösterilmiştir.

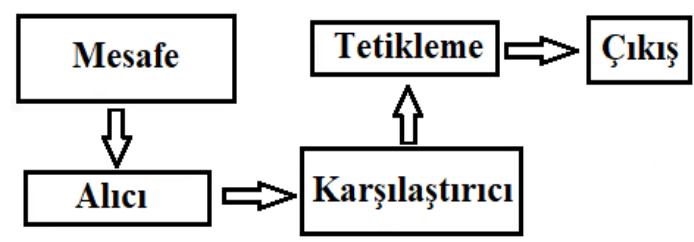

Şekil 4: Sistemin sembolik akış diyagramı

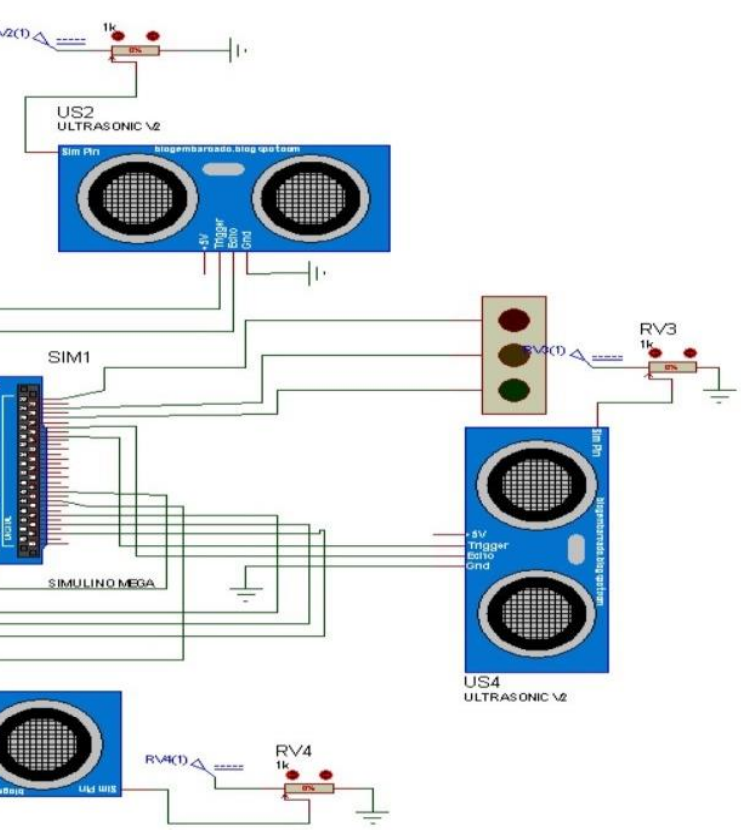

Şekil 5: Tasarlanan sistemin proteus programındaki devre şeması 
Proteus programında simülasyonu yapılan çalışmanın uygulama kısmı arduino mega 2560 modülü üzerinden yapılmıştır. Arduino mega 2560 modülünün üzerinde 54 adet giriş pini bulunmaktadır. Bu çalışmada, ilk aşamada 4 adet ultrasonik mesafe sensörü kullanılmıştır. Ultrasonik mesafe sensörlerinin test pinlerine 1 adet ayarlanabilir potansiyometre ve diğer pinlerine ise 5 volt de gerilim uygulanmıştır. $\mathrm{Bu}$ uygulamanın amacı 4 kavşaklı bir yolda her bir ultrasonik mesafe sensörünün algılayabildiği uzaklıkta herhangi bir vasıtanın olup olmadığının tespit edilmesidir. Sırasıyla her bir ultrasonik mesafe sensörüne bağlı potansiyometrelerin değerleri 0'dan 100 değerine kadar arttırılıp azaltılmıştır. Bu sayede Kuzey, Güney, Doğu ve Batı yönlerinde bulunan trafik lambalarının yanıp yanmadığı kontrol edilmiştir. Yapılan kontroller sonucunda proteus programındaki kurulan devrede trafik yoğunluğunu tespit etmek amacıyla beșinci bir ultrasonik mesafe sensörü batı yönündeki kavşağa eklenmiştir. Daha sonra proteus programında başarı ile benzetimi yapılan çalışmanın uygulama kısmına geçilmiştir. Şekil 6'da uygulama çalışmasında kullanılan trafik sinyalizasyon sisteminin iş akış diyagramı gösterilmiştir.

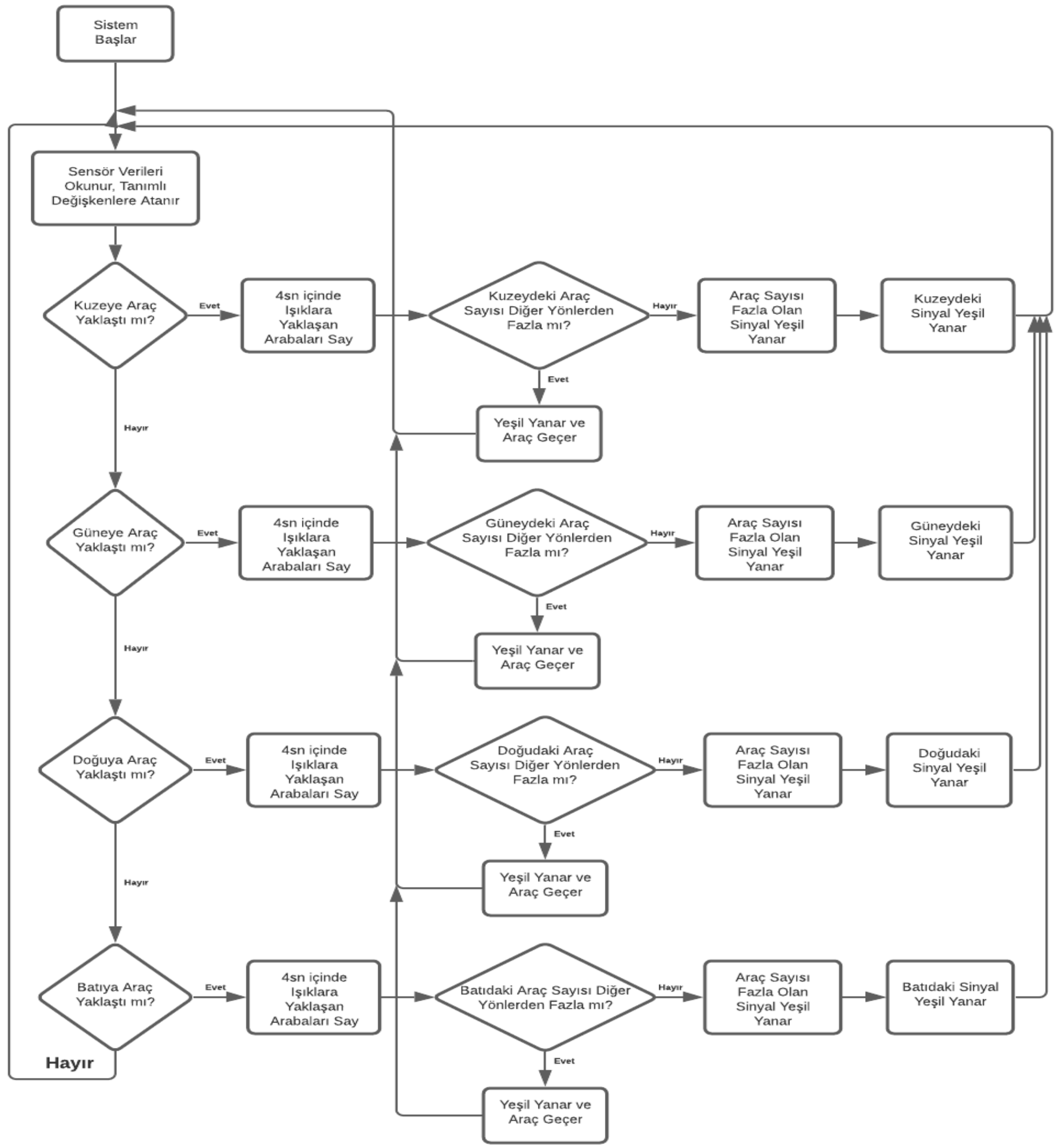

Şekil 6: Uygulanan trafik sinyalizasyon sisteminin iş akış diyagramı 
$\mathrm{Bu}$ aşamada 4 kavşaklı bir yolda trafik yoğunluğuna bağlı olarak sinyalizasyon sisteminin karşılaştııılması yapılarak, geçiş üstünlüğü hakkının hangi yöne verilmesi gerektiği ile ilgili uygulama çalışması yapılmıştır. Şekil 7'de uygulama çalışmasına ait maket hali gösterilmiştir. Uygulama 5 aşamada gerçekleşmiştir

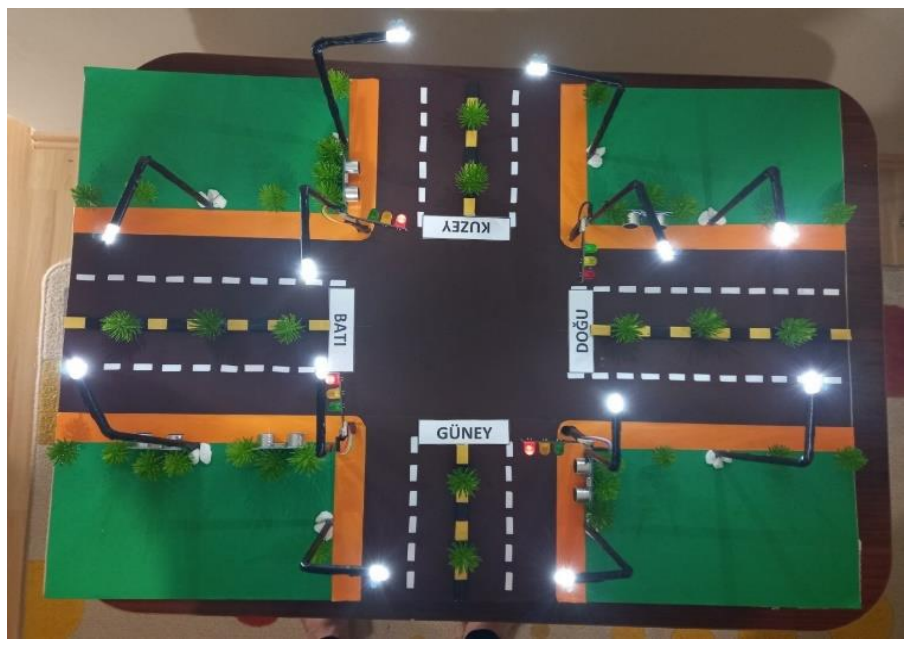

Şekil 7: Akıllı kavşak sisteminin uygulama maketi görünümü

İlk aşamasında kavşağın kuzey, güney, doğu ve batı yönlerinde vasita bulunmamaktadır. Sirasiyla vasitalar kuzey yönüne doğru yaklaşmaktadır. Vasıtanın yaklaştığını algılayan kuzey yönündeki ultrasonik mesafe sensörü arduino kartına sinyal göndermektedir. $\mathrm{Bu}$ durumu algılayan sistem diğer yönlerden gelen vasıta olup olmadığını denetlemektedir. Eğer diğer yönlerde bulunan ultrasonik mesafe sensörlerinden vasita algılanmaz ise güney yönündeki trafik lambası buradaki vasıta için yeşil ışı̆̆ı̆ yanmasını sağlamakta ve buradaki vasıtanın geçişine izin vermektedir. Örneğin kuzey yönünden bir vasıta yaklaşır ve sistemde diğer yönlerinden vasita gelmediği ultrasonik mesafe sensörleri tarafindan algılanır ise, kuzey yönünden gelen vasıta bekletilmeden yeşil ışık yakılarak geçiş imkânı sağlanır. Benzer yöntem farklı yönlerden gelen vasıtalar içinde tekrarlanabilir.

İkinci aşamada 4 kavşaklı yolun kuzey ve batı yönlerine doğru iki vasıta yaklaştı̆̆ 1 görülmektedir. İlk olarak kavşağın kuzey yönündeki vasıta kavşağa gelmekte ve ardından iki saniye içerisinde diğer vasıta batı yönündeki kavşağa gelmektedir. Burada sinyalizasyon sistemi ultrasonik mesafe sensörlerinin göndermiş oldukları verileri inceleyerek ilk olarak hangi vasıtanın kavşağa geldiğini tespit etmektedir. Ardından kuzey yönündeki vasıta için trafik geçiş üstünlüğünü oluşturmaktadır. Kuzey yönündeki vasıta geçişini tamamladıktan sonra batı yönündeki vasıta için trafik lambası yeşil yanmakta ve buradaki vasıta geçişi sağlanmaktadır. Şekil 8'de bu senaryoya uygun akıllı kavşak sisteminin kuzeybatı yönündeki enstantane görüntüsü gösterilmiştir.

Üçüncü aşamada kuzey, batı ve güney yönlerinden gelen 3 vasıta 4 kavşaklı yolda karşılaşmaktadır. İlk kavşağa gelen vasıta batı yönündeki, ikincisi güney yönündeki ve son olarak gelen ise kuzey yönündeki vasıta olarak kabul edilmiştir. Beklenen kavşaklarda herhangi bir trafik yoğunluğu olmaması durumunda (her kavşakta bir vasıta olması durumu) trafik sinyalizasyon sisteminin ilk algıladığı vasıta olarak batı yönündeki vasıtaya geçiş üstünlüğü vermektedir. Daha sonra sinyalizasyon sistemi, ikinci algılanan vasıta olarak güney yönündeki vasıtaya geçiş üstünlüğü sağlamakta ve son olarak ise kuzey yönündeki vasıtaya geçiş izni vermektedir. Şekil 9'da söz konusu senaryo uygulanırken alınan bir enstantane görüntüsü gösterilmiştir.

e-ISSN: 2148-2683

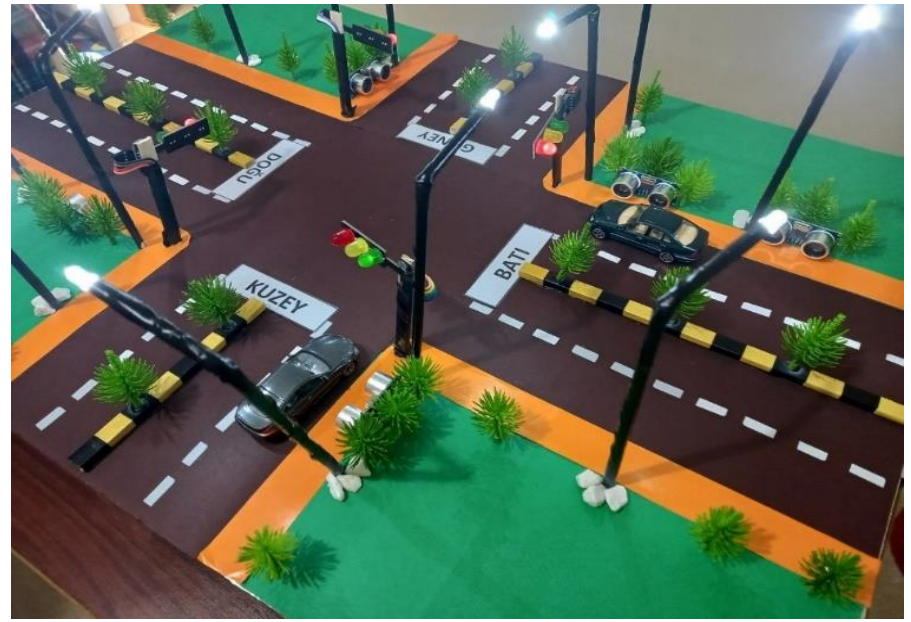

Şekil 8: Akıllı kavşak sisteminin kuzeybatı yönünden görünümü

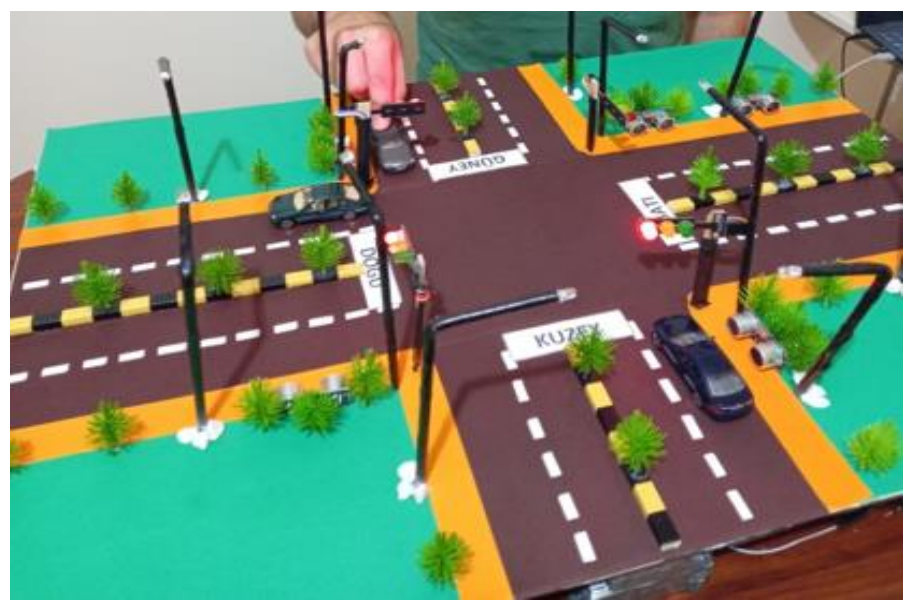

Şekil 9: Akıllı kavşak sisteminde aynı anda üç vasıta olması durumunu gösterir enstantane görünümü

Üçüncü aşamada farklı kombinasyonlardaki vasıtalar kuzey, güney ve doğu yönlerinden kavşağa yaklaşmaktadır. İlk kavşağa gelen vasita kuzey yönündeki, ikincisi güney yönündeki ve son olarak gelen ise doğu yönündeki vasıta olarak kabul edilmiştir. Söz konusu üç yönde herhangi bir trafik yoğunluğu olmadığı durumda sinyalizasyon sistemi sirasiyla ilk olarak kuzey yönündekine daha sonra güney ve doğu yönlerindekilere geçiş üstünlüğü vermektedir. Şekil $10^{\prime}$ da söz konusu senaryo uygulanırken alınan bir enstantane görüntüsü gösterilmiştir.

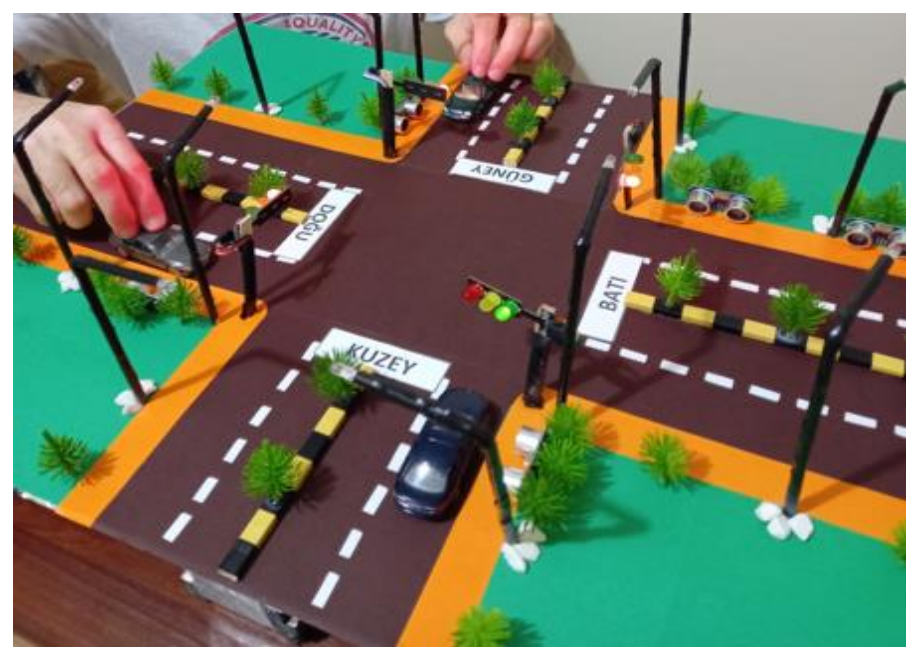

Şekil 10: Akıllı kavşak sisteminde her yönde bir vasıta olması durumunu gösterir enstantane görünümü 
Dördüncü aşamada ise trafik yoğunluğuna bağlı olarak geçiş üstünlügü verilecek olan sistem yapısı incelenmiştir. Bu sistemde ilk vasıta kuzey yönünden kavşağa gelmektedir. İki saniye süre içerisinde batı yönünden ilave iki vasıta daha kavşağa gelmektedir. Bu sistemde trafik yoğunluğu bulunmadığı şartlarda inceleme yapılmış olsaydı, kavşağa ilk gelen vasıtaya geçiş üstünlüğü verilmesi gerekirdi. Ancak trafik yoğunluğu batı yönünde olduğu için trafik sinyalizasyon sistemi karşılaştırma yapmakta ve geçiş üstünlüğünü trafik yoğunluğunun olmuş olduğu batı yönüne vermektedir. Daha sonrasında ise kavşağa ilk gelen vasıta olan güney yönündeki vasıtaya geçiş izni vermektedir. Şekil 11'de söz konusu senaryo uygulanırken alınan bir enstantane görüntüsü gösterilmiştir.

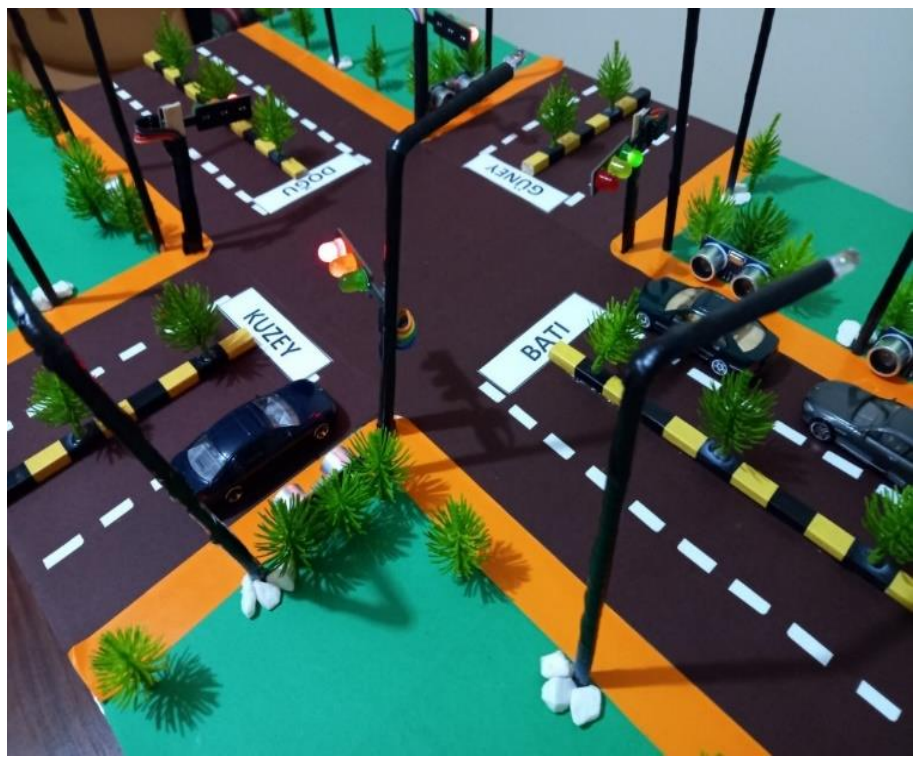

Şekil 11: Akıllı kavşak sisteminde iki yöndeki trafik yoğunluğuna bağll sinyalizasyon sistemi tepkisinin görünümü

Beşinci aşamada trafik yoğunluğuna bağlı olarak geçiş üstünlüğü verilecek olan sistem yapısı incelenmekte ve ilk vasıta doğu yönünden kavşağa yaklaşmaktadır. İki saniye süre içerisinde kuzey ve batı yönlerinden de vasıtalar kavşağa yaklaşmaktadır. Trafik yoğunluğu dikkate alınmadığı takdirde, kavşağa ilk gelen doğu yönündeki vasıtaya daha sonra kuzey yönündeki vasıtaya son olarak da batı yönündeki vasıtaya geçiş üstünlüğü verilmesi gerekirdi. Ancak trafik yoğunluğu batı yönünde olduğu için sinyalizasyon sistemi ilk olarak batı yönüne geçiş üstünlüğü vermektedir. Daha sonra güney ve doğu yönlerindeki vasıtalar için sinyalizasyon sistemi karşılaştırma yapmakta ve ilk kavşağa gelen vasita olan doğu yönündeki vasita için daha sonrasında da güney yönündeki vasita için trafik geçiş üstünlüğü sağlanmaktadır. Şekil 12'de söz konusu senaryo uygulanırken alınan bir enstantane görüntüsü gösterilmiştir.

Farklı bir senaryoda kavşağa yakın zamanlarda her yönden vasitaların yaklaşması durumudur. İlk vasıta güney yönünden ikincisi doğu yönünden geldiği kabul edilmektedir. Daha sonra batı yönünden iki adet vasıta gelmekte ve sonrasında kuzey yönünden bir adet vasıta gelmektedir. Sinyalizasyon sistemi trafik yoğunluğunu batı yönünde algılayacağı için batı yönündeki trafik 1şıklarının yeşil yanmasını sağlamakta ve bu yöndeki trafik yoğunluğunu azaltmaktadır. Daha sonra diğer yönlerde eşit sayıda vasita bulunduğu için sırasıyla güney, doğu ve kuzey yönlerinden gelen vasıtalara yeşil 1şık yakarak geçiş imkânı sağlamaktadır. Şekil 13'te söz konusu senaryo uygulanırken alınan bir enstantane görüntüsü gösterilmiştir.

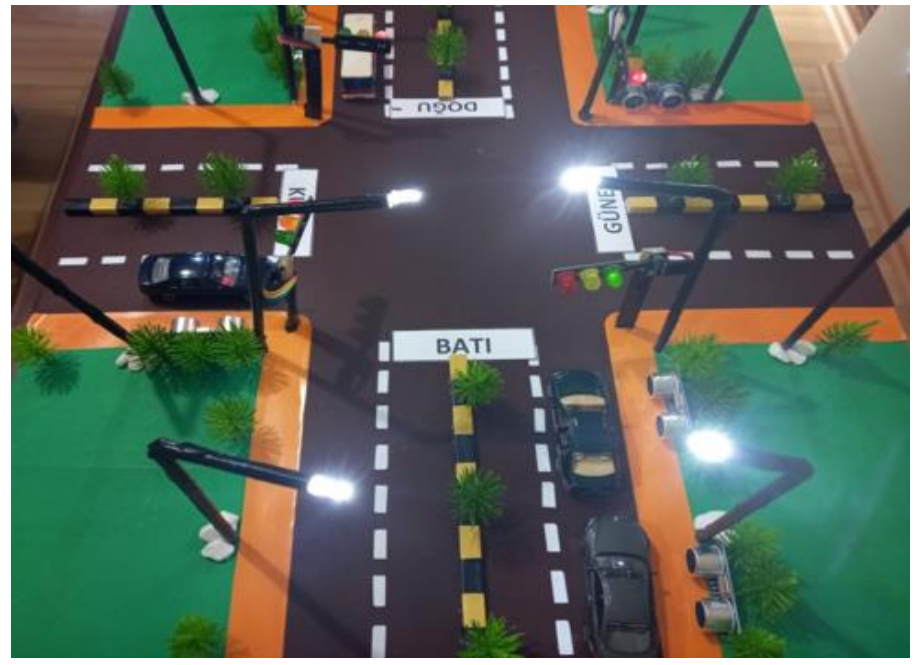

Şekil 12: Akıllı kavşak sisteminde üç yöndeki trafik yoğunluğuna bağll sinyalizasyon sistemi tepkisinin görünümü

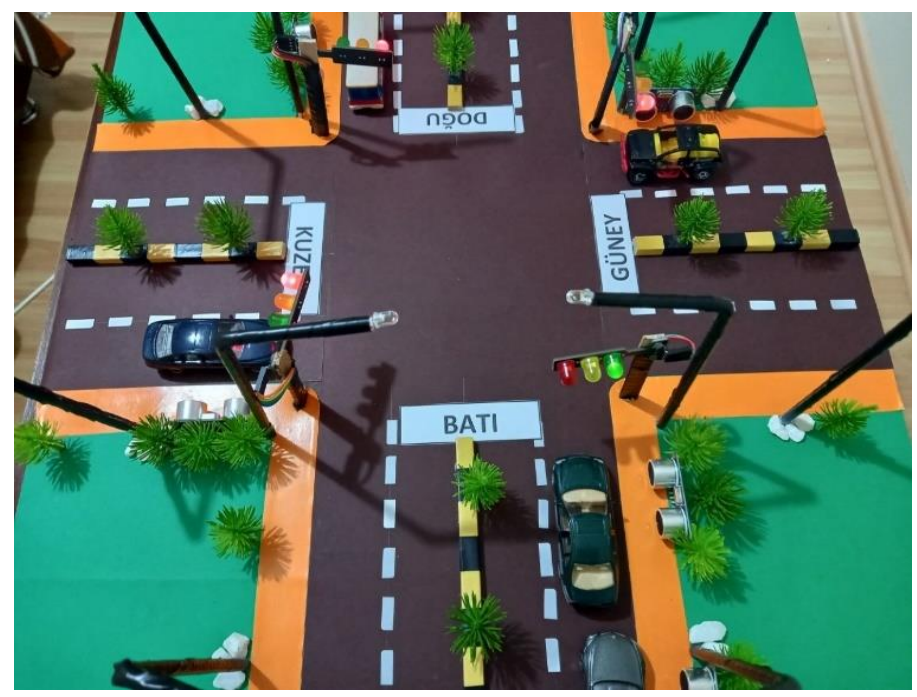

Şekil 13: Akıllı kavşak sisteminde her yönde vasıta olması durumundaki sinyalizasyon sistemi tepkisinin görünümü

\section{Sonuçlar ve Öneriler}

Yapılan araştırmalar sonucunda dünyada ve ülkemizde orantısız olarak artan kentleşme yatay mimari yapısından dikey mimarisine geçiş durumu vasıta trafiğini arttırmakta ve ulaşımda çeşitli sorunları ortaya çıkarmaktadır. Bu çalışmada, söz konusu sorunları ortadan kaldırmak için bazı yöntemler üretilmeye çalışılmıştır. Bu yöntemlerden en önemlisi akıllı kavşak yönetim sistemidir. Akıllı kavşak sinyalizasyon sistemleri karayollarındaki trafik yoğunluklarının düzenlenmesini amaçlamaktadır. Teknolojinin gelişmesiyle birlikte söz konusu akıllı sistemlerde dinamik olarak değişmektedir. Akıllı kavşak sinyalizasyon sistemlerinin insan hayatına entegre olması, trafik kazaları gibi maddi ve manevi kayıpları önlemenin yanısıra trafikteki zaman kayıplarınıda önlemektedir.

Uygulanan trafik sinyalizasyon sisteminde belirli noktalara konumlandırılmış ultrasonik mesafe sensörleri vasıtasıyla trafik 1şıklarının yanma süreleri kavşaklardaki vasıta sayılarına göre anlık olarak ayarlanmaktadır. Bu sayede trafik akışının gereksiz yere durması engellenmektedir. Vasita trafiği fazla olan karayollarında trafik yoğunluğu azalmakta ve ulaşım daha rahat hale gelmektedir. Akıllı kavşak sinyalizasyon sistemleri sayesinde birçok olumlu etki ortaya çıkmaktadır. Bu etkiler; 
- Trafik akışı hızlanmaktadır.

- Vasitaların karayollarındaki bekleme süreleri en aza indirilmektedir.

- Trafikteki bekleme süresi azalacağından dolayı, sürücülerin trafik kurallarına uymama eğilimi azalmakta ve bu sayede trafik kazası olma olasılığ 1 düşmektedir.

- Araç egzozlarından çevreye salınan karbondioksit ve diğer zehirli gazların emisyon miktarları azaltılarak çevre kirliliğinin en aza indirilmesi sağlanacaktır.

- Araçlar trafikte daha az yakıt tüketecek ve bu durum ülke ekonomisine büyük katkı sağlayacaktır.

\section{Teșekkür}

$\mathrm{Bu}$ çalışmaya vermiş oldukları desteklerden dolayı Yavuz Yağmuroğlu ve Yasin Aynacı'ya çok teşekkür ederim.

\section{Kaynakça}

Avani, P., Sawant, M.K., Sawant, S., Deshmukh, R.S. (2017). A review on adaptive traffic controls systems. International Journal of Latest Engineering and Management Research (IJLEMR), ISSN: 2455-4847, 2(1), 52-57.

Azimirad, E., Pariz, N., \& Sistani, M.B.N. (2010). A novel fuzzy model and control of single intersection at urban traffic network. IEEE Systems Journal, 4(1), 107-111, doi: 10.1109/JSYST.2010.2043159.

Balta, M., Özçelik, İ. (2019). Şehir içi kavşak yönetim sistemleri için SDN temelli bir VANET mimari önerisi. Gazi Üniversitesi Mühendislik Mimarlık Fakültesi Dergisi, 34(3), 1451-1468, doi:10.17341/gazimmfd.460544.

Dağüstü, H.Ş. (2010). Trafik yönetiminde kavşak trafiğinin kontrolü için bir sinyal zamanlama modeli. Yıldız Teknik Üniversitesi Fen Bilimleri Enstitüsü, Yüksek Lisans Tezi, İstanbul, Türkiye.

Firdous, M., Din Iqbal, F.U., Ghafoor, N., Qureshi, K., \& Naseer, N. (2019). Traffic light control system for four-way intersection and T-crossing using fuzzy logic. IEEE International Conference on Artificial Intelligence and Computer Applications (ICAICA'19), 178-182, doi:10.1109/ICAICA.2019.8873518.

Gonca, C.K., Gülsün, B. (2019). Adaptif trafik yönetim sistemleri. OHS Academy İ̧s Să̆lı̆̆ ve Güvenliği Akademi Dergisi, 2(1), 32-40.

Güler, Z. (2013). Akıllı trafik kontrol sistemi. Hacettepe Üniversitesi Fen Bilimleri Enstitüsü, Yüksek Lisans Tezi, Ankara, Türkiye.

Hoyer, R., Jumar, U. (1994). Fuzzy control of traffic lights. Proc. IEEE International Conference on Fuzzy Systems, 15261531.

Kelsey, R., Bisset, K., \& Jamshidi, M. (1993). A simulation environment for fuzzy control of traffic systems. IFAC Proceedings, 26(2), 753-756.

Kim, Jongwan. (1997). A fuzzy logic control simulator for adaptive traffic management. Proc. IEEE International Conference on Fuzzy Systems, 1519-1524.

Lei, C., Guojiang, S., Wei, Y. (2006). The traffic flow model for single intersection and its traffic light intelligent control strategy. $6^{\text {th }}$ World Congress on Intelligent Control and Automation doi:10.1109/WCICA.2006.1713650, 8558-8562.

Niittymaki, P., Jarkko. (1997). Isolated traffic signals-vehicle dynamics and fuzzy control. Ph.D. Thesis, Helsinki University of Technology, Civil and Environmental Engineering, Finland.
Ozkaya, U., \& Seyfi, L. (2016). A novel fuzzy logic model for intelligent traffic systems. Electronics World, 122(1960), 3639.

Öztürk, Z., Çalış, E. A. (2017). Monoray ulaşım sisteminin özellikleri ve diğer kentiçi ulaşım araçları ile karşılaştırılması. İstanbul Teknik Üniversitesi, Fen Bilimleri Enstitüsü, Yüksek Lisans Tezi, İstanbul, Türkiye.

Pappis, C.P., Mamdani, E.H. (1977). A fuzzy logic controller for a traffic junction. IEEE Transactions on systems, Man and Cybernetics, 707-717.

Ramzanzad, M., \& Rashidy Kanan, H. (2013). A new method for design and implementation of intelligent traffic control system based on fuzzy logic using FPGA. $13^{\text {th }}$ Iranian Conference on Fuzzy Systems (IFSC), 1-4. doi: 10.1109/IFSC.2013.6675630.

Samadi, S., Rad, A.P., Kazemi, F.M., Jafarian, H. (2012). Performance evaluation of intelligent adaptive traffic control systems: A case study. Journal of Transportation Technologies, http://dx.doi.org/10.4236/jtts.2012.23027, 2(1), 248-259.

Tataru, A.I., Druga, C.N. (2019). Designing and realization an ECG based the Arduino Mega 2560 development board. IOP Conferences Series: Materials Science and Engineering, Annual Session of Scientific Papers (IMT ORADEA'19), paper 568 (012081), doi:10.1088/1757-899X/568/1/012081.

Tzes, A., McShane, Kim, S. (1995). Expert fuzzy logic traffic signal control for transportation networks. $65^{\text {th }}$ Annual Meeting Instute of Transportation Engineers, Denver USA, 154-158.

Tzes, A., Nikolakopoulos, G., Koutroulis, I. (2005). Development and experimental verification of a mobile client-centric networked controlled system. European Journal of Control, 11(3), 229-241.

Tunç, A. (2003). Trafik Mühendisliği ve Uygulamaları. Asil Yayın Dağıtım.

Yılmaz, M., Altınkaya H., \& Ekmekci, D. (2019). Control of railway signalization between Zonguldak Ankara with neurofuzzy approach. Scientific Meeting on Electrical-Electronics \& Biomedical Engineering and Computer Science (EBBT'19), 1-4. doi:10.1109/EBBT.2019.8741690. 